\title{
OCORRÊNCIA DE Rochinia umbonata (STIMPSON, 1871) NA PLATAFORMA CONTINENTAL DOS ESTADOS DO AMAPÁ E PARÁ/REVIZEE-NORTE (CRUSTACEA: DECAPODA: BRACHYURA: MAJIDAE)
}

\author{
Kátia Cristina de Araújo SILVA \\ Engenheira de Pesca - Centro de Pesquisa e Extensão Pesqueira do Norte do Brasil \\ (CEPNOR/IBAMA - MMA) \\ Marilena RAMOS-PORTO \\ Professor Adjunto do Departamento de Pesca da UFRPE \\ Israel Hidenburgo Aniceto CINTRA
} Engenheiro de Pesca - Centro de Pesquisa e Extensão Pesqueira do Norte do Brasil (CEPNOR/IBAMA - MMA)

Girlene Fábia Segundo VIANA Professor Substituto do Departamento de Pesca da UFRPE

\section{RESUMO}

Os exemplares de Rochinia umbonata (Stimpson, 1871) foram capturados ao largo da plataforma continental dos Estados do Amapá e Pará, durante campanhas de prospecções pesqueiras para recursos vivos demersais, realizadas nos meses de novembro e dezembro de 1996, a bordo do Navio de Pesquisa "Almirante Paulo Moreira" - CEPNOR/IBAMA, utilizando-se rede de arrasto de fundo para crustáceos. Durante a captura, foram anotados os seguintes dados: local e data, número de exemplares, sexo, quantidade de fềmeas ovadas, comprimento e largura da carapaça, peso total e profundidade. Os espécimens estudados, duas fềmeas ovadas e três machos; um macho; uma fêmea, foram capturados a 186m, 434m e 621 metros de profundidade, respectivamente. Estes foram identificados nos laboratórios de Carcinologia do Centro de Extensão Pesqueira do Norte do Brasil (CEPNOR/IBAMA- MMA) e do Departamento de Pesca da Universidade Federal Rural de Pernambuco (UFRPE). A área de ocorrência desta espécie, mencionada na literatura, incluía a Carolina do Norte, Mar do Caribe, Golfo do México, Nicarágua, Suriname e Guiana Francesa. O atual registro amplia sua distribuição, em direção sul, até o Estado do Pará, Brasil.

Palavras-chave: Caranguejo; Majidae; REVIZEE-N; Rochinia umbonata; primeira ocorrência.

\section{ABSTRACT}

Occurrence of Rochinia Umbonata (Stimpson, 1871) at the Continental Shelf of Amapá and Pará States (Revizee-North) (Crustacea: Decapoda: Brachyura: \section{Majidae)}

Specimens of Rochinia umbonata (Stimpson, 1871) were captured on the continental shelves of Amapá and Pará States along the cruises of fishery prospection on November and December of 1996 by the R/V "Almirante Paulo Moreira" under supervision of the Centro de Pesquisa e Extensão Pesqueira do Norte do Brasil (CEPNOR/IBAMA-MMA) with otter trawl for crustaceans. Additional data such place and date of capture, number of specimens, sex, number of females with ova, carapace length and width, total weight and depth were also noted. The studied specimens consist of two females with ova and three males, one male and one female which were captured at 186, 434 and 621 meters depth, respectively. These specimens were identified at the

Trab. Oceanog. Univ. Fed. PE, Recife, 27(1):169-173, 1999. 
Laboratório de Carcinologia do Centro de Pesquisa e Extensão Pesqueira do Norte do Brasil (CEPNOR/IBAMA-MMA) and Laboratório de Carcinologia of Departamento de Pesca of Universidade Federal Rural do Pernambuco (UFRPE). The known area of distribution of this species included North Carolina, Caribbean Sea, Gulf of Mexico, Suriname, and French Guiana. This record extends the known distribution southward to the State of Pará, Brazil.

Key words: Crab; Majidae; REVIZEE-N; Rochinia umbonata, first record.

\section{INTRODUÇÃO}

Durante as Campanhas de Prospecções para Recursos Demersais, direcionadas aos Crustáceos - Programa REVIZEE/Norte - foram coletadas várias espécies de caranguejos, entre as quais destacava-se $R$. umbonata, pertencente a família Majidae

Os Majidae são conhecidos como "aranhas do mar", sendo encontrados desde as zonas costeiras até maiores profundidades. De acordo com Williams (1984), estes indivíduos apresentam quelípedes especialmente móveis, geralmente de tamanho semelhante às outras patas, com dedos retos. Segundo artículo da antena bem desenvolvido, geralmente fundido ao epístoma, e, freqüentemente, com a fronte. Órbitas mais ou menos incompletas. Cerdas arqueadas quase sempre presentes. Macho com abertura coxal. Palpo do maxilípede externo articulado na extremidade, ou no ângulo ântero-interno do meropodito. Primeiro par de pleópodo, nos machos, excedendo o segundo, em comprimento.

\section{MATERIAL E MÉTODOS}

Foram estudados sete espécimes, coletados durante a terceira e quarta Campanhas de Prospecções Pesqueiras, executadas a bordo do Navio de Pesquisa "Almirante Paulo Moreira", objetivando-se realizar o levantamento do Potencial dos Recursos Vivos na Zona Econômica Exclusiva no Setor Norte do Brasil (REVIZEE/NO), através de uma rede de arrasto para camarões.

O material foi acondicionado em basquetas etiquetadas e conservado em câmara refrigerada. Após o desembarque, as amostras foram conservadas em álcool a $75 \%$, e analisadas posteriormente nos laboratórios de Carcinologia do CEPNOR e do Departamento de Pesca da UFRPE, encontrando-se depositadas na coleção da primeira instituição.

Para a identificação, foram utilizados os trabalhos de Takeda (1983) e Williams (1984), e, para a classificação, Melo (1996).

Foram anotados: local de captura (posição geográfica), data, número de exemplares, sexo, quantidade de fêmeas ovadas, comprimento e largura da carapaça (em milímetro), peso total (grama) e profundidade.

\section{RESULTADOS}

Infraordem Brachyura Latreille, 1803

Seção Oxyrhyncha Latreille, 1803

Superfamília Majoidea Samouelle, 1819

Família Majidae Samouelle, 1819

Subfamília Pisinae Dana, 185

Rochinia umbonata (Stimpson, 1871)

(Figuras 1 e 2)

Descricão - Carapaça piriforme, recoberta por densa pubescência; superfície dorsal com nove tubérculos, dos quais um, nas regiôes metagástrica e cardíaca e dois maiores, nas regiões branquiais, com formas variadas e geralmente truncados, ou com extremidades cegas; margem hepática com um espinho e um tubérculo cegos; ângulo póstero-lateral da região branquial com um espinho e um tubérculo; um tubérculo cego na margem posterior da carapaça. Margem pré-orbital apresentando um tubérculo direcionado obliquamente para cima e para fora. Cornos rostrais moderadamente divergentes, de comprimento variável, em função da idade. Quelípedes delgados; meropodito com alguns tubérculos na parte proximal superior e com um espinho distal. Patas ambulatórias longas e cilíndricas com um tubérculo na extremidade distal de cada mero (Takeda, 1983).

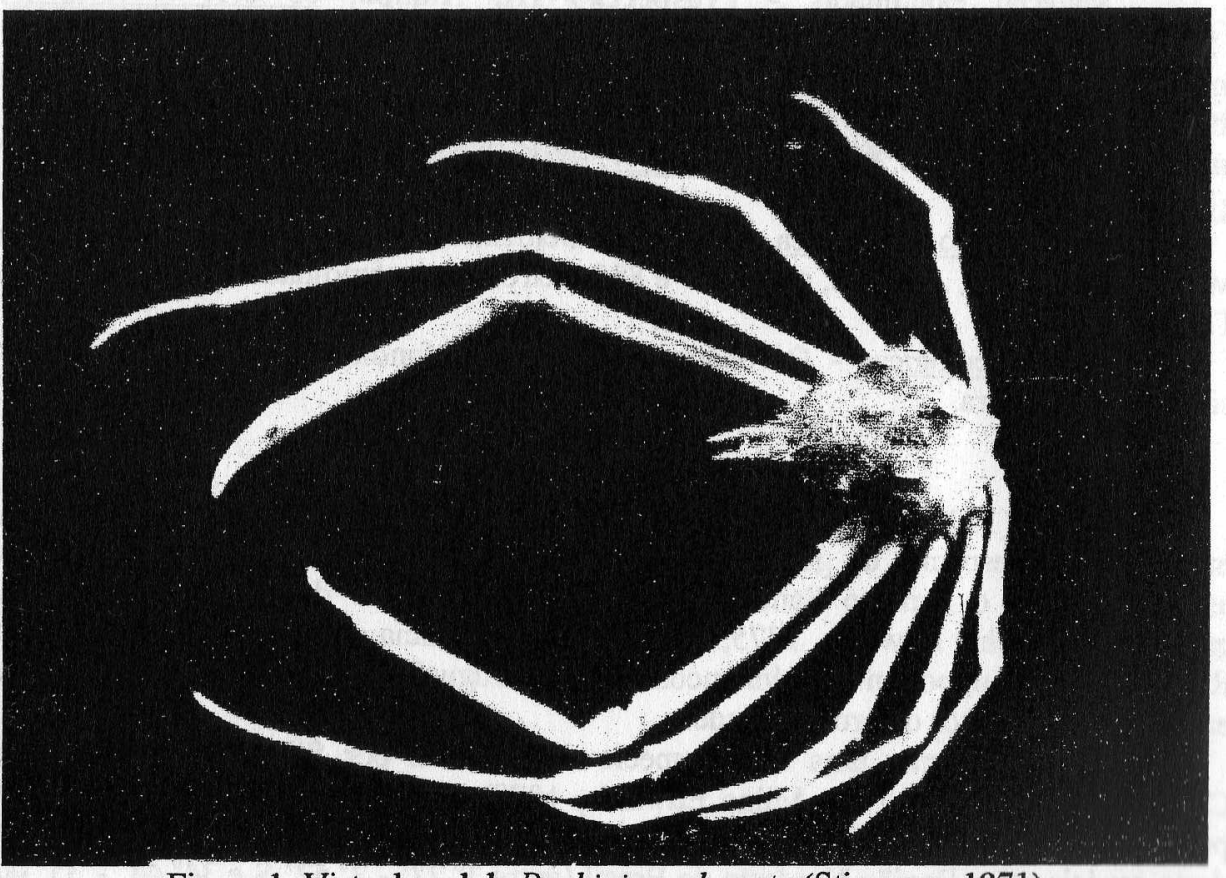

Figura 1: Vista dorsal de Rochinia umbonata (Stimpson, 1871) 


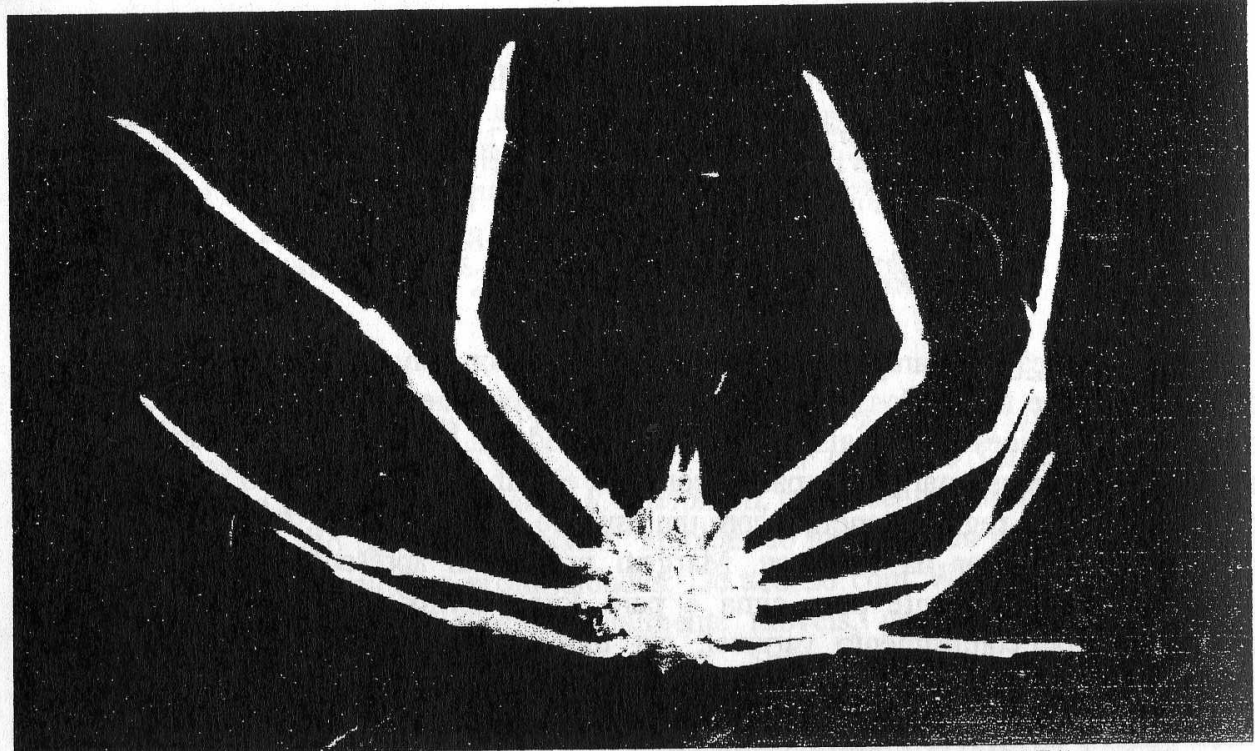

Figura 2: Vista ventral de Rochinia umbonata (Stimpson, 1871)

Material examinado .- Prospecção III, Amapá, $\underline{\underline{03} 43^{\prime} \mathrm{N}-48^{\circ} 53^{\prime} \mathrm{W}}$, $15 / 11 / 1996,2$ fềmeas ovadas, $(48 \mathrm{~mm}, 38 \mathrm{~mm}, 38,7 \mathrm{~g}$ e $65 \mathrm{~mm}, 44 \mathrm{~mm}, 72,2 \mathrm{~g}) \mathrm{e} 3$ machos ( $55 \mathrm{~mm}, 44 \mathrm{~mm}, 47,5 \mathrm{~g} ; 61 \mathrm{~mm}, 40 \mathrm{~mm}, 46,8 \mathrm{~g}$ e $62 \mathrm{~mm}, 49 \mathrm{~mm}, 52,3 \mathrm{~g}), 186$ metros. Prospeção IV, Pará, $02^{\circ} 40^{\prime} \mathrm{N}-47^{\circ} 44^{\prime} \mathrm{W}, 07 / 12 / 1996,1$ macho $(69 \mathrm{~mm}, 46$ $\mathrm{mm}, 43,5 \mathrm{~g}), 434$ metros. $02^{\circ} 43^{\prime} \mathrm{N}-47^{\circ} 39^{\prime} \mathrm{W}, 07 / 12 / 1996,1$ fềmea $(21 \mathrm{~mm}, 21 \mathrm{~mm}, 3,9$ g); 621 metros.

Distribuição geográfica - Atlântico Ocidental: Carolina do Norte, Golfo do México, Nicarágua, Antilhas; entre 155 e 885 metros de profundidade (Williams, 1984; Takeda, 1983).

Notas Ecológicas - Os dados atuais para profundidade concordam com os citados na literatura

\section{COMENTÁRIOS E CONCLUSÕES}

Melo (1996) em recente revisão dos caranguejos do litoral brasileiro, menciona duas espécies do gênero Rochinia para o Brasil: $R$. confusa Tavares, 1991, assinalada para o Espirito Santo, entre 590 e 730 metros de profundidade, e $R$. gracilipes A. Milne Edwards, 1875, com área de ocorrência entre o Rio de Janeiro e o Rio Grande do Sul, porém também encontrada no Uruguai, na Argentina e na Antártida, entre 15 e 175 metros de profundidade.

Posteriormente, uma outra espécie foi incluída por Silva, Ramos-Porto \& Cintra (1997), $R$ crassa (A. Milne Edwards, 1879), coletada no Amapá, a 330m de profundidade, em fundo arenoso. Sankarankutty et al. (1998), ampliaram a distribuição desta espécie até a Região Nordeste do Brasil (entre $3^{0} 27^{\prime}-3^{0} 52^{\prime}$ S e $34^{\circ} 44^{\prime}-35^{\circ} 00$ W), ocorrendo entre 100 e 600 metros de profundidade.

172
No que diz respeito a Rochinia umbonata, com o resultado atual, sua área de ocorrência é ampliada mais ao sul, até o Estado do Pará, Brasil.

Além disso, o gênero Rochinia, em águas brasileiras, fica representado, até o presente momento, por quatro espécies, a saber: $R$. confusa, $R$. crassa, $R$. gracilipes e $R$. umbonata.

\section{AGRADECIMENTOS}

Os autores expressam seus agradecimentos ao Oceanógrafo Getúlio Rincón Filho, pela confecção do Abstrat e ao Engenheiro Agrônomo Lauro Satoro Itó, pelo trabalho fotográfico.

\section{REFERÊNCIAS BIBLIOGRÁFICAS}

MELO, G. A. S. 1996. Manual de Identificação dos Brachyura (caranguejos e siris) do litoral brasileiro. São Paulo : Plêiade / FAPESP. 604 p.

SANKARANKUTTY, C.; OLIVEIRA, J. E. L.; FERREIRA, A. C. \& CUNHA, K. M. F. 1998. On two spider crabs (Crustacea: Decapoda: Majidae) from the northeast of Brasil. Nauplius, Rio Grande, v. 6, p. 187-188.

SILVA, K. C. A.; RAMOS-PORTO, M. \& CINTRA, I. H. A. 1997. Registro de Rochinia crassa (A. Milne Edwards, 1879) em águas brasileiras (Crustacea: Decapoda: Brachyura). Boletim Técnico-Cientifico, CEPENE, Tamandaré, CEPENE, Rio Formoso, Pernambuco, v.5, n.1, p. 9-13.

TAKEDA, M. 1983. Crustaceans and mollusks trawled off Suriname and French Guiana. Tóquio: Japan Marine Fishery Resoure Research Center, 354 p.

WILLIAMS, A. B. 1984. Shrimps, lobsters, and crabs of the eastern United States, Maine to Florida. Washington: Smithsonian Institution Press. 550 p. 